\title{
INFLUÊNCIA DA TEMPERATURA NA PRODUÇÃO DE BIOGÁS A PARTIR DE DEJETOS DA BOVINOCULTURA DE LEITE
}

\author{
Caroline Monique Tietz ${ }^{2}$, Dilcemara Cristina Zenatti ${ }^{3}$, Armin Feiden ${ }^{4}$, Karine Natani \\ Lupatini $^{5}$, Arlindo Fabrício Corrêia ${ }^{6}$
}

\begin{abstract}
${ }^{1}$ Aceito para publicação em $2^{\circ}$ trimestre de 2014
${ }^{2}$ Mestranda do Programa de Pós-Graduação em Desenvolvimento Rural Sustentável - Universidade Estadual do Oeste do Paraná, Campus de Marechal Cândido Rondon/PR, Brasil, carol.tietz@ hotmail.com;

${ }^{3}$ Dr ${ }^{\mathrm{a}}$. em Engenharia Agrícola e Professora do Curso Superior de Tecnologia em Biocombustíveis - Universidade Federal do Paraná, Setor Palotina/PR, Brasil, dilzenatti@gmail.com;

${ }^{4}$ Dr. em Energia na Agricultura e Professor do Programa de Pós-Graduação em Desenvolvimento Rural Sustentável - Universidade Estadual do Oeste do Paraná, Campus de Marechal Cândido Rondon/PR, Brasil, armin.feiden@gmail.com;

${ }^{5}$ Mestranda do Programa de Pós-Graduação em Energia na Agricultura - Universidade Estadual do Oeste do Paraná, Campus de Cascavel/PR, Brasil, karinelupatini@gmail.com;

${ }^{6}$ Doutorando do Programa de Pós-Graduação em Agronomia - Universidade Estadual do Oeste do Paraná, Campus de Marechal Cândido Rondon/PR, Brasil, afcorreia.pr@gmail.com.
\end{abstract}

\section{Resumo}

Os biodigestores permitem transformar resíduos poluidores em energia e biofertilizante. Dentre os diferentes tipos de biodigestores, surgiu recentemente o modelo Bioköhler, amplamente utilizado na região Oeste do Paraná e que ainda é pouco estudado. Este trabalho buscou avaliar a influência da temperatura na produção de biogás a partir de dejetos da bovinocultura de leite. O experimento foi realizado entre os dias 17/12/2012 e 02/03/2013, em um biodigestor de 20 $\mathrm{m}^{3}$ localizado na Estação Experimental Antonio Carlos dos Santos Pessoa, pertencente à UNIOESTE - Campus de Marechal Cândido Rondon. Foram obtidos os dados de temperatura interna e externa do biodigestor, volume de biogás produzido e teor de $\mathrm{CH}_{4}, \mathrm{CO}_{2}$ e outros gases presentes no biogás. Os resultados indicam que a temperatura média interna se manteve dentro da faixa mesofílica e que somente a temperatura média da região superior não seguiu o comportamento da temperatura externa ao biodigestor, os resultados também mostram que os teores dos gases, entre uma semana e outra, acompanharam a produção média de biogás, e esta produção foi influenciada pela variabilidade da temperatura interna e externa do biodigestor. 
Palavras-chave: Biodigestor, digestão anaeróbia, metano.

\title{
INFLUENCE OF TEMPERATURE ON BIOGAS PRODUCTION FROM WASTE OF DAIRY CATTLE
}

\begin{abstract}
The digesters allow polluters to turn waste into energy and bio-fertilizers. Among the different types of digesters, the Bioköhler model, widely used in western Paraná and that has been little studied recently emerged. This study evaluated the influence of temperature on biogas production from manure of dairy cattle. The experiment was carried out between 17/12/2012 and 02/03/2013 on a $20 \mathrm{~m}^{3}$ digester located at the Experimental Station of Antonio Carlos dos Santos Pessoa belonging to UNIOESTE - Campus Marechal Cândido Rondon. Data from internal and external temperature of the digester, biogas volume and content of $\mathrm{CH}_{4}, \mathrm{CO}_{2}$ and other gases present in the biogas were obtained. The results indicate that the average indoor temperature is maintained within the mesophilic range, and that only the average temperature of the upper region does not follow the behavior of the temperature outside the digester, the results also show that the amounts of gases from one week to another, followed average biogas production, and this production was influenced by the variability of internal and external temperature of the digester.
\end{abstract}

Keyword: Digester, anaerobic digestion, methane.

\section{Introdução}

O acelerado crescimento da população mundial e a necessidade de manutenção de seu bem estar resulta na obrigação de expandir a produção de alimentos. Diante disto, a agropecuária passou por um rápido avanço tecnológico, acentuando sua participação nos impactos provocados ao ambiente, tornando evidente a necessidade de implantação de políticas e ampliação dos investimentos e pesquisas em relação ao desenvolvimento de sistemas de produção mais sustentáveis (AMORIN et al., 2004; SOUZA e CAMPOS, 2007).

Os resíduos orgânicos gerados na agropecuária, também denominados biomassa residual, podem se tornar contaminantes do meio caso manejados inadequadamente. Entretanto, independente da sua origem, todo resíduo poderá ter seu descarte minimizado através de uma análise de suas propriedades e potenciais de uso (MIRANDA et al., 2006).

Revista Brasileira de Energias Renováveis, v. 3, p. 80-96, 2014 
Dentre os resíduos agropecuários, o da bovinocultura merece destaque, tendo em vista que o rebanho bovino brasileiro é um dos maiores do mundo. Segundo dados de 2012 do Instituto Brasileiro de Geografia e Estatística (IBGE), o efetivo nacional de bovinos em 2011 chegou a 212,7 milhões de cabeças, com maiores concentrações no Centro-Oeste, Norte e Sudeste. O estado do Paraná conta com mais de 9,4 milhões de cabeças. Na produção de leite, o Brasil ocupa hoje a quinta posição no ranking mundial, atrás apenas da Índia, Estados Unidos, Paquistão e China (IFCN, 2012).

Sendo assim, um volume considerável de dejetos animais é gerado todos os dias em sistemas de confinamento de bovinos leiteiros. O manejo inadequado desses dejetos é um dos causadores da poluição de águas superficiais e subterrâneas, devido ao transporte desse material pela ação da chuva. Além disso, por se tratarem de compostos orgânicos com micro e macronutrientes, propiciam um recinto que oferece água, temperatura e abrigo, preferido por muitos vetores associados à transmissão de zoonoses, além de inúmeras doenças epidêmicas, intestinais e respiratórias (AMARAL et al., 2004).

Estes compostos orgânicos também apresentam alto teor energético, podendo servir como potencial fonte de energia, por meio da utilização de biodigestores (SOUZA e CAMPOS, 2007).

A biodigestão anaeróbia é um dos inúmeros processos existentes para o tratamento de resíduos. Constitui-se em um método no qual os compostos orgânicos dos dejetos podem ser convertidos em biogás, com diversas aplicações na produção agropecuária, ao mesmo tempo em que minimiza os impactos ambientais decorrentes da disposição inadequada dos resíduos (PECORA et al., 2008; AMORIN et al., 2004; MIRANDA et al., 2006).

A capacidade de produção de biogás varia conforme a espécie animal. Os dejetos de bovinos produzem cerca de $270 \mathrm{~m}^{3}$ de biogás/tonelada (MOURA, 2012).

O biogás é composto tipicamente por uma mistura variada de gases, dentre eles faz-se presente em maior quantidade o metano $\left(\mathrm{CH}_{4}\right)$ e o dióxido de carbono $\left(\mathrm{CO}_{2}\right)$, podendo chegar a conter entre $40 \%$ a $75 \%$ e $25 \%$ a $40 \%$, respectivamente, dependendo da eficiência do processo (FARIA, 2012).

A realização e eficiência da biodigestão dependem de diversos fatores, como tipo de substrato usado no processo, $\mathrm{pH}$, acidez, alcalinidade, temperatura, concentração de sólidos, etc. Dentre estes, a temperatura influencia diretamente a atividade microbiana e velocidades das reações bioquímicas, sendo de suma importância nos sistemas biológicos (CASTRO e CORTEZ, 1998; MIRANDA et al., 2006). 
Este trabalho de pesquisa teve como objetivo verificar a influência das variações na temperatura na produção de biogás durante o processo de biodigestão anaeróbia de dejetos da bovinocultura leiteira.

\section{Material e Métodos}

A pesquisa foi conduzida, no período de 17 de dezembro de 2012 a 02 de março de 2013, junto a Estação Experimental Prof. Dr. Antonio Carlos dos Santos Pessoa, situada na Linha Guará do município de Marechal Cândido Rondon - PR, pertencente ao Núcleo de Estações Experimentais da Universidade Estadual do Oeste do Paraná - Campus de Marechal Cândido Rondon.

O biodigestor experimental presente é da marca Bioköhler, com câmara de biodigestão confeccionada com fibra de vidro pela empresa Bakof Tec.

A câmera de biodigestão é formada pela união de duas caixas d'água de $10 \mathrm{~m}^{3}$ cada, sendo uma caixa d'água normal (totalmente enterrada no solo) e a outra tendo o seu fundo arredondado (ficando fora do solo), contendo uma saída para manutenção, permitindo a abertura da mesma em caso de necessidade. Ambas as caixas tem seu material reforçado em função da pressão hidráulica do líquido e do gás. A câmara de biodigestão tem capacidade de $20 \mathrm{~m}^{3}$, com volume útil de 19,56 $\mathrm{m}^{3}$, está instalada no sentido vertical, conforme a Figura 1, e possui sistema de alimentação intermitente e de fluxo ascendente.

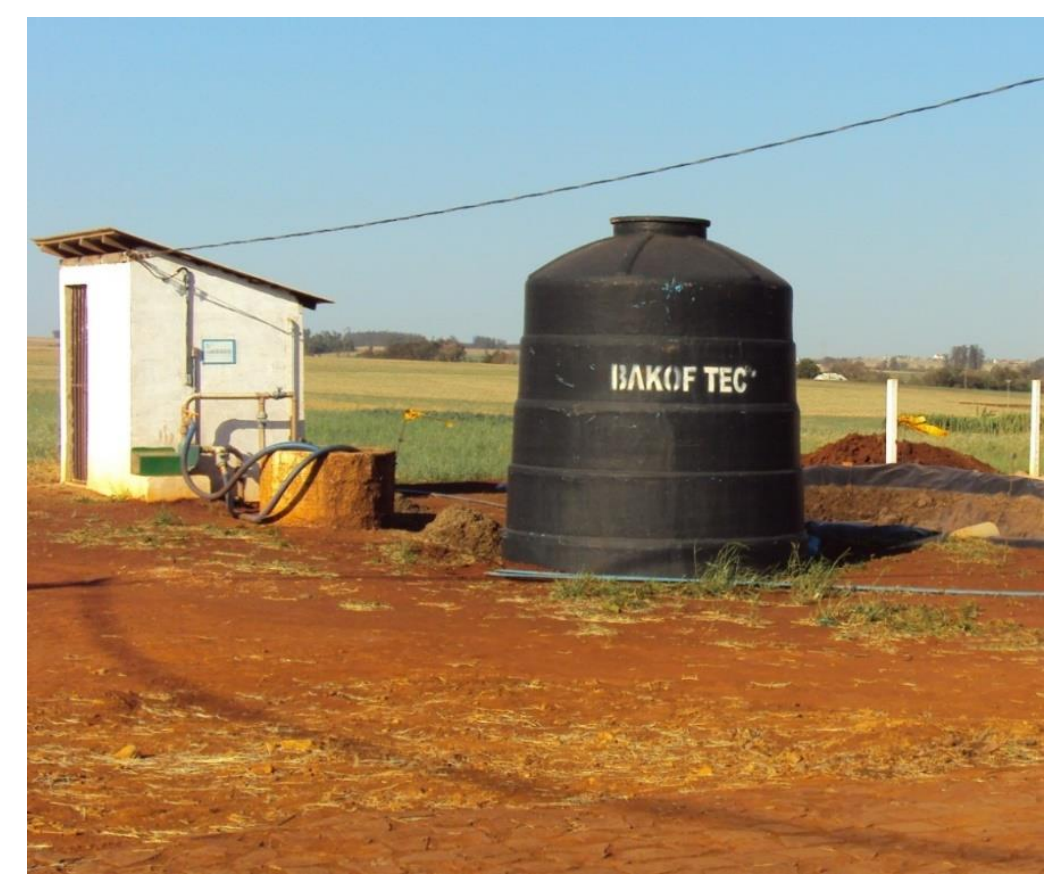

FIGURA 1: Vista parcial da Estação Experimental de produção de biogás (UNIOESTE). 
A canalização de afluente e biogás é toda subterrânea para proteção do sol, da chuva e de possíveis impactos que venham a danificá-la.

O dejeto bovino era raspado do estábulo e acumulado no início do encanamento, onde era misturado com água e a mistura resultante escoava por dentro do encanamento e se deslocava por gravidade até a caixa de alimentação do biodigestor. Este deslocamento ocorria por diferença hidráulica visto que a mistura era feita de forma a manter uma concentração de sólidos totais entre 8 e 12\%, que naturalmente é fluida e se comporta como um líquido (CASTRO e CORTEZ, 1998).

O biodigestor então era alimentado por esta mistura de água e dejetos bovinos provenientes da própria Estação Experimental, que conta com 10 bezerros e 24 vacas (leiteiras e novilhas) da raça holandesa, que eram alimentados com feno, ração e silagem. As vacas permaneciam no estábulo por aproximadamente 5 horas, enquanto os bezerros, 14 horas. A operação e o manejo do biodigestor eram realizados diariamente no período da manhã.

O tempo de detenção hidráulica (TDH) foi calculado utilizando-se a Equação 1, sendo o volume da biomassa total em fermentação igual ao volume útil e a alimentação diária foi medida pela média das alimentações semanais, obtendo-se assim um TDH de aproximadamente 70 dias.

\section{$\mathbf{T D H}=\mathbf{V} / \mathbf{Q}$}

Equação (1)

Onde:

$\mathrm{V}=$ volume útil do biodigestor $\left(\mathrm{m}^{3}\right)$;

$\mathrm{Q}=\operatorname{vazão}\left(\mathrm{m}^{3} / \mathrm{dia}\right)$.

A análise estatística foi realizada utilizando análise de variância seguido do teste $\mathrm{F}$ para verificar a diferença entre os dados de produção de biogás $\left(\mathrm{m}^{3}\right)$ e teste de Tukey para médias à 5\% de significância de erro, por meio do ambiente estatístico R (R Core Team, 2013) e pacote estatístico complementar ExpDes.pt (FERREIRA et al., 2013).

O experimento consistiu no monitoramento das variáveis: temperatura interna do biodigestor, temperatura ambiente, volume de biogás produzido e teor de $\mathrm{CH}_{4}, \mathrm{CO}_{2}$ e outros gases $\left(\mathrm{O}_{2}, \mathrm{CO}\right.$ e $\left.\mathrm{H}_{2} \mathrm{~S}\right)$ presentes no biogás.

A temperatura interna do biodigestor foi medida diariamente, com o auxílio de 3 termopares tipo J, sendo o termopar superior colocado a $80 \mathrm{~cm}$ abaixo do nível máximo da 
biomassa em fermentação, o intermediário a 2,50 m e o inferior a 4,20 m, conforme a Figura 2. Os dados foram armazenados em intervalos de 15 minutos por meio de um registrador eletrônico FieldLogger, marca Novus, com 8 canais analógicos por módulo, precisão de 0,2\% da faixa máxima, o que equivale a $\pm 1^{\circ} \mathrm{C}$.

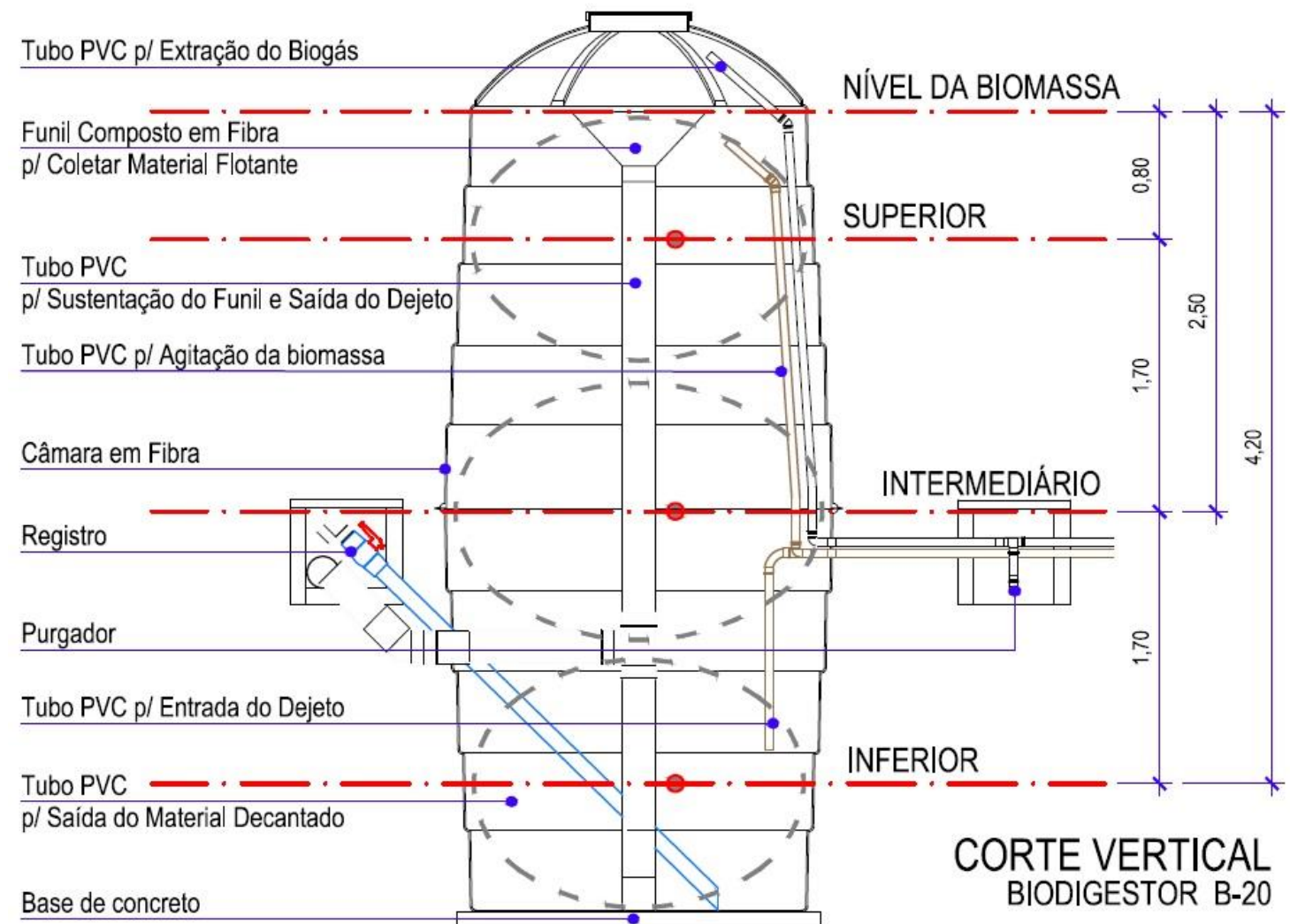

FIGURA 2: Região superior, intermediária e inferior da medição da temperatura interna do biodigestor.

FONTE: Adaptado de Ferreira (2010).

A temperatura ambiente foi cedida pela Estação Climatológica Automática de Marechal Cândido Rondon - PR, Código A 820, localizada na própria Estação Experimental. As temperaturas foram medidas por um sensor de temperatura do ar, elemento sensível sensor resistivo de platina Pt 100, da marca Vaisala, com temperatura de operação de -40 a $+60{ }^{\circ} \mathrm{C}$, tempo de resposta de $500 \mathrm{~ms}$ e acurácia de $\pm 0,2^{\circ} \mathrm{C}$.

$\mathrm{O}$ volume de biogás produzido foi medido através de um medidor de gás modelo $\mathrm{G}$ 0,6 fabricado pela LAO Indústria. Este tipo de medidor é comumente utilizado em edifícios para medir GLP (gás liquefeito de petróleo), porém tem o inconveniente de ser afetado pelo gás sulfídrico e, portanto, ter baixa durabilidade quando usado com biogás. O volume foi registrado de forma contínua, e a leitura feita diariamente, antes da alimentação do biodigestor. 
$\mathrm{O}$ teor de $\mathrm{CH}_{4}, \mathrm{CO}_{2}$ e outros gases presentes no biogás produzido foi medido por um analisador de gás portátil da marca Dräger X-am 7000, obtendo os dados por meio de sensores infravermelhos para $\mathrm{CH}_{4}$ e $\mathrm{CO}_{2}$, e outros sensores para os demais gases.

\section{Resultados e Discussão}

Os valores médios das temperaturas, durante os 76 dias de experimento, considerando a temperatura interna $\left({ }^{\circ} \mathrm{C}\right)$ em três pontos diferentes (região superior, intermediária e inferior) e a temperatura externa $\left({ }^{\circ} \mathrm{C}\right)$ ao biodigestor, estão apresentados na Figura 3.

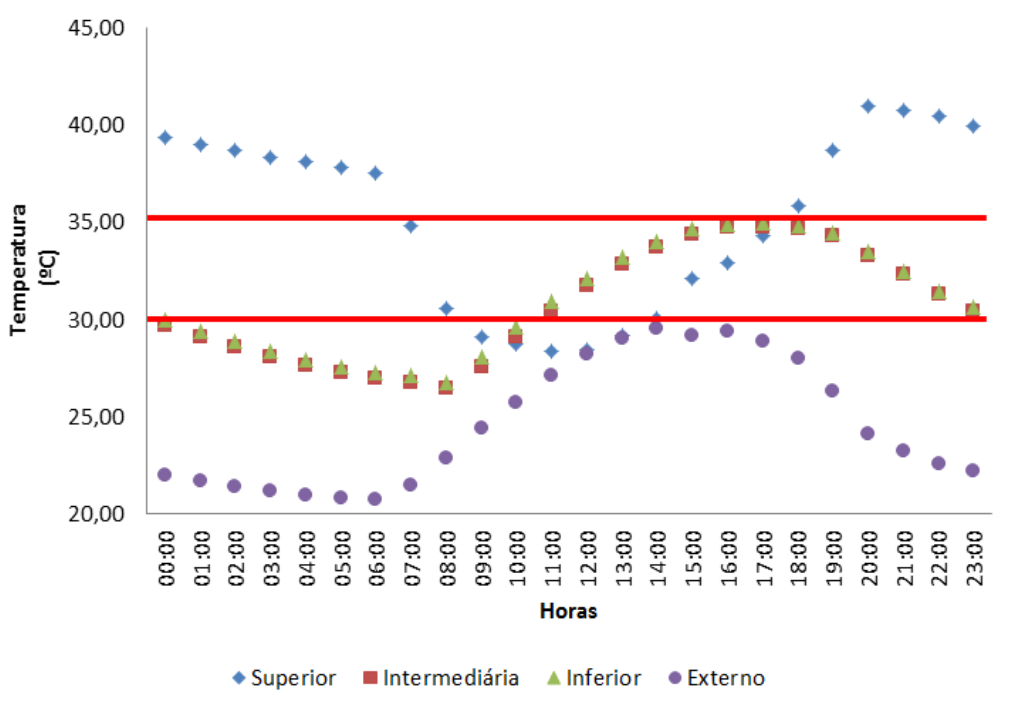

FIGURA 3: Variação diária média da temperatura interna e externa ao biodigestor.

Apesar de muitos autores terem opiniões diferentes sobre qual é a faixa de temperatura ideal para ocorrer a digestão anaeróbia, a grande maioria concorda que acima de $10^{\circ} \mathrm{C}$ o sistema funciona (HENN et al., 2004). Conforme Maurer e Winkler (1980) e Nogueira (1986), para otimizar a digestão anaeróbia, dentro da faixa mesofílica, as temperaturas devem se aproximar da faixa ideal de 30 a $35^{\circ} \mathrm{C}$.

Neste trabalho observou-se que os valores diários médios obtidos ficaram dentro desta faixa ideal, na região intermediária e inferior, das 11:00 às 23:00 horas. Entre 00:00 às 01:00 e às 10:00 horas os valores foram próximos a faixa ideal, porém não atingiram $30^{\circ} \mathrm{C}$, mantendose entre 29,08 e 29,94 ${ }^{\circ} \mathrm{C}$ e das 02:00 às 09:00 horas se mantiveram abaixo da faixa ideal de temperatura, atingindo um mínimo de $26,42{ }^{\circ} \mathrm{C}$ e máximo de $28,81^{\circ} \mathrm{C}$. 
No caso da região superior os valores permaneceram na área de temperatura ideal das 07:00 às 08:00 horas e das 14:00 às 17:00 horas e após este último período os valores ultrapassaram a faixa ideal de temperatura até às 06:00 horas. Entre 09:00 e 13:00 horas, os valores novamente saíram da faixa ideal, apresentando médias de temperatura entre 28,34 e $29,17^{\circ} \mathrm{C}$.

Estes resultados indicaram que mesmo a temperatura média na região superior, intermediária e inferior não estando dentro da faixa ideal de temperatura para a produção de biogás em todos os horários, ela se encontrou na faixa mesofílica, entre 20 a $45^{\circ} \mathrm{C}$, conforme Salomon (2007).

Observa-se também o comportamento diferenciado da região superior em relação às demais, o que evidencia notadamente a troca de energia térmica das massas no interior do reator.

Na Figura 4 observa-se os resultados da temperatura média às 01:00 (A), 09:00 (B) e 17:00 (C) horas, no período de 17/12/2012 a 02/03/2013, semanalmente. Determinou-se as análises nestes três horários com a finalidade de observar a influência da temperatura no período noturno, durante a manhã e a tarde, bem como se as alterações ocorridas no período anterior afetaram o período seguinte. 
(A)

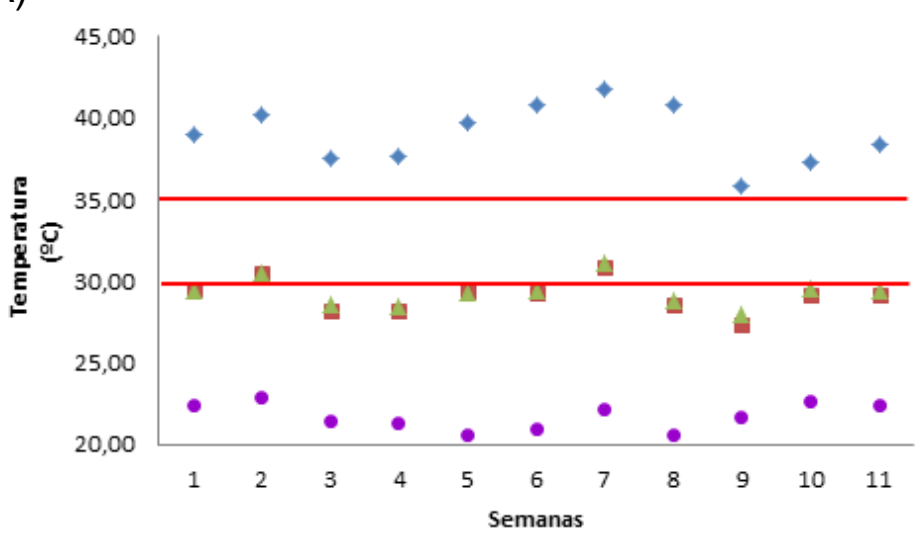

(B)

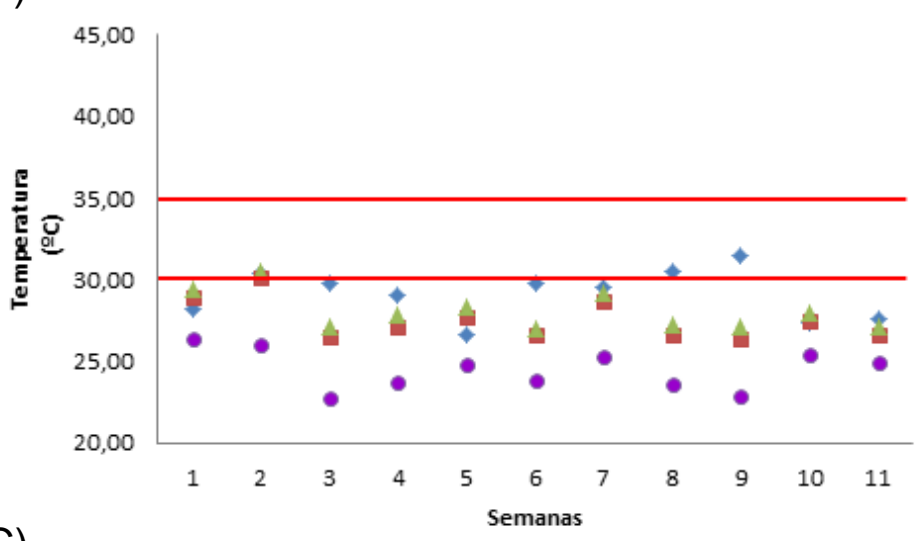

(C)

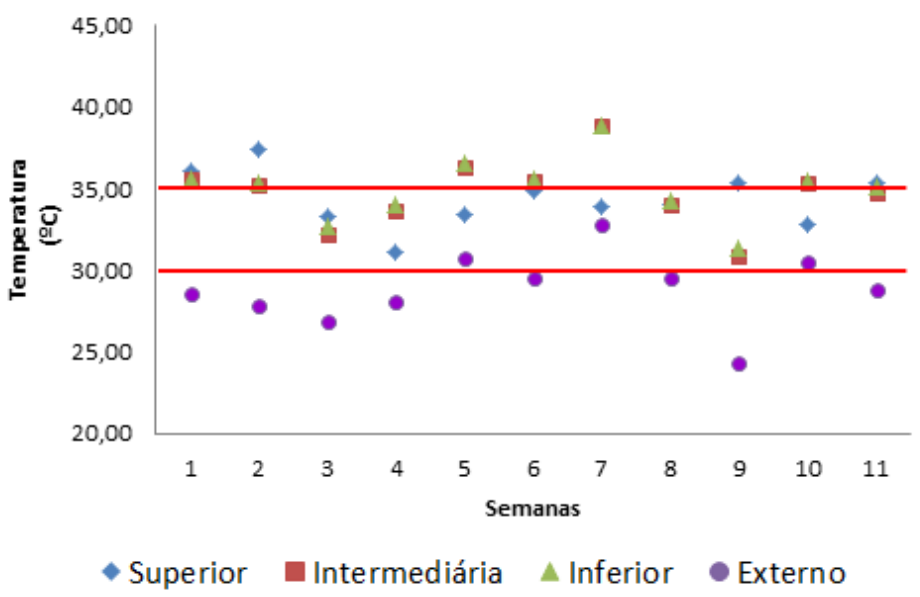

FIGURA 4: Temperatura média semanal às 01:00 (A), 09:00 (B) e 17:00 (C) horas.

Na Figura 4 (A), observou-se que a temperatura média semanal à 01:00 hora, da região superior, não se manteve em nenhum momento dentro da faixa ideal esperada e nas regiões intermediária e inferior somente na $2^{\mathrm{a}} \mathrm{e} 7^{\mathrm{a}}$ semana.

Na Figura 4 (B), observou-se que na $2^{\mathrm{a}}, 8^{\mathrm{a}}$ e $9^{\mathrm{a}}$ semana a temperatura média semanal às 09:00 horas na região superior se manteve dentro da faixa ideal de temperatura. Nas regiões intermediária e inferior, somente a $2^{\mathrm{a}}$ semana esteve dentro da temperatura ideal. 
Observou-se na Figura $4(\mathrm{C})$, que os valores de temperatura média semanal às 17:00 horas ficaram dentro da faixa ideal de temperatura para produção de biogás nas regiões intermediária e inferior na $3^{\mathrm{a}}, 4^{\mathrm{a}}, 8^{\mathrm{a}}, 9^{\mathrm{a}}$ e $11^{\mathrm{a}}$ semana, já na região superior, da $3^{\mathrm{a}}$ a $8^{\mathrm{a}}$ e também na $10^{\mathrm{a}}$ semana.

Os dados presentes na Figura 4 mostram que às 09:00 horas a maioria dos valores se encontraram abaixo da faixa ideal de temperatura devido à influência do resfriamento noturno, diferentemente dos dados observados às 17:00 horas, os quais mostram que o aquecimento ocorrido durante o dia afetou relevantemente a temperatura interna neste horário. No período noturno, no qual se observou uma redução na temperatura externa, percebeu-se claramente a troca de energia térmica que ocorreu entre as massas internas do biodigestor. Logo à 01:00 hora, nota-se que na região superior a temperatura apresentou-se mais elevada que as demais, pois a massa aquecida tende a subir com a finalidade de manter as características térmicas (TOFFOLI, 2008).

As regiões intermediária e inferior ficam em contato direto com o solo, e a região superior não. Isso explica o fato da região superior se diferenciar das demais, pois sofre influência dos fatores externos, como vento, nuvens, chuva, orvalho, temperatura, entre outros.

$\mathrm{Na}$ Figura 5 observa-se os dados médios semanais de produção de biogás, $\mathrm{CH}_{4}, \mathrm{CO}_{2} \mathrm{e}$ outros gases.

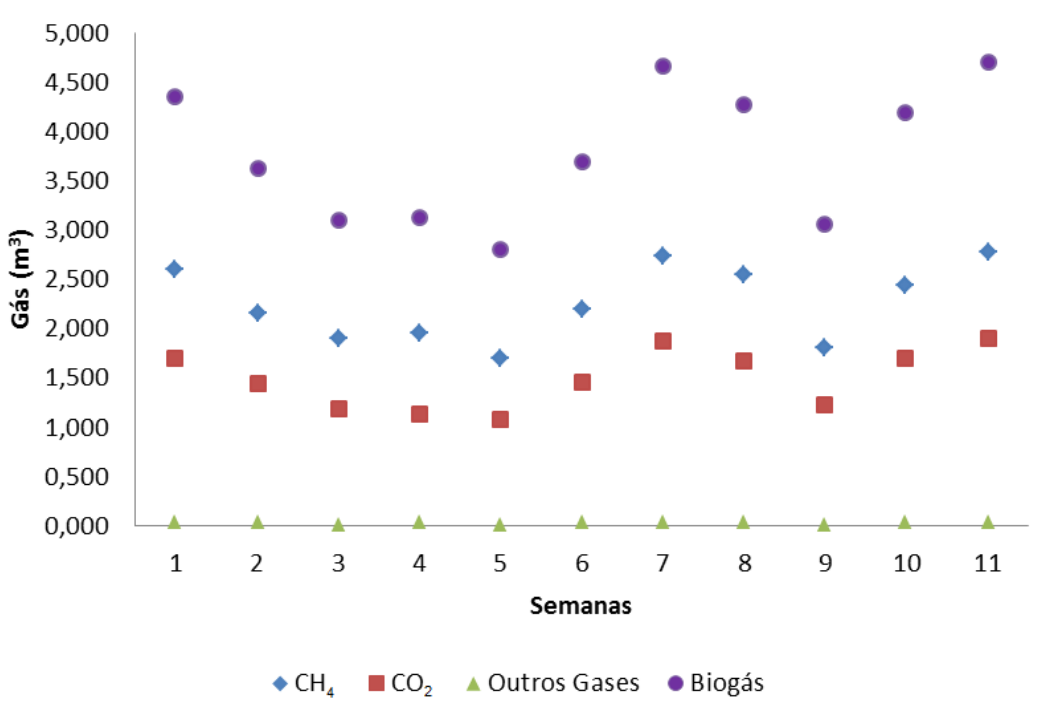

FIGURA 5: Dados médios semanais de produção de biogás, $\mathrm{CH}_{4}, \mathrm{CO}_{2}$ e outros gases.

O comportamento da variação dos teores de $\mathrm{CH}_{4}, \mathrm{CO}_{2}$ e outros gases acompanharam a produção média de biogás, que se manteve entre $2,79 \mathrm{~m}^{3}$ ( $5^{\mathrm{a}}$ semana) e $4,70 \mathrm{~m}^{3}$ (11 $1^{\mathrm{a}}$ semana). 
Sendo os teores médios semanais $59,78 \%, 39,41 \%$ e $0,81 \%$, respectivamente, demonstrando a estabilidade do reator quanto à produção de metano.

Os resultados presentes na Tabela 1 demonstram os dados médios semanais do teor de $\mathrm{CH}_{4}, \mathrm{CO}_{2}$ e outros gases, em porcentagem, presentes no biogás produzido.

TABELA 1: Dados médios semanais do teor de $\mathrm{CH}_{4}, \mathrm{CO}_{2}$ e outros gases, presentes no biogás produzido.

\begin{tabular}{cccc}
\hline SEMANA & $\mathbf{C H}_{\mathbf{4}}(\boldsymbol{\%})$ & $\mathbf{C O}_{\mathbf{2}}(\boldsymbol{\%})$ & $\begin{array}{c}\text { OUTROS GASES } \\
(\%)\end{array}$ \\
\hline 1 & 59,99 & 39,18 & 0,83 \\
2 & 59,44 & 39,76 & 0,80 \\
3 & 60,80 & 38,40 & 0,80 \\
4 & 62,48 & 36,68 & 0,84 \\
5 & 60,48 & 38,71 & 0,81 \\
6 & 59,52 & 39,69 & 0,79 \\
7 & 58,73 & 40,47 & 0,79 \\
8 & 59,68 & 39,51 & 0,81 \\
9 & 59,06 & 40,16 & 0,79 \\
10 & 58,40 & 40,80 & 0,80 \\
11 & 59,06 & 40,16 & 0,79 \\
\hline
\end{tabular}

Com base nos dados presentes na Tabela 1, observou-se que os teores de $\mathrm{CH}_{4}$ se mantiveram de acordo com a literatura, que segundo Faria (2012), deve compreender seus valores entre $40-75 \%$. O maior teor foi observado na $4^{\mathrm{a}}$ semana, contando com $62,48 \%$ de $\mathrm{CH}_{4}$ e o menor foi de $58,40 \%$, na $10^{\text {a }}$ semana, uma diferença de $4,08 \%$. Em relação ao teor de $\mathrm{CO}_{2}$, o qual o mesmo autor menciona que deve estar na faixa de $25-40 \%$, observou-se que apenas na $7^{\mathrm{a}}, 9^{\mathrm{a}}, 10^{\mathrm{a}}$ e $11^{\mathrm{a}}$ semana essa faixa foi sensivelmente ultrapassada, não chegando a $1 \%$ acima do esperado. O menor teor foi observado na $4^{\mathrm{a}}$ semana, com $36,68 \%$ e o maior na $10^{\mathrm{a}}$ semana, com $40,80 \%$, uma diferença de $4,12 \%$ de $\mathrm{CO}_{2}$. O teor de outros gases se manteve abaixo de $1 \%$.

Machado et al. (2009), avaliando a produção de biogás utilizando dejetos bovinos leiteiros com diferentes tempos de armazenamento com exposição ao ar, obteve em média $70,48 \%$ de $\mathrm{CH}_{4}$. Os valores encontrados pelo autor foram superiores aos registrados no presente 
estudo, o que pode ser justificado pela prévia exposição ao ar que proporcionou uma préfermentação do resíduo.

A Figura 6 apresenta a média de produção de biogás acumulado na semana relacionada a média de temperatura interna e externa do biodigestor.

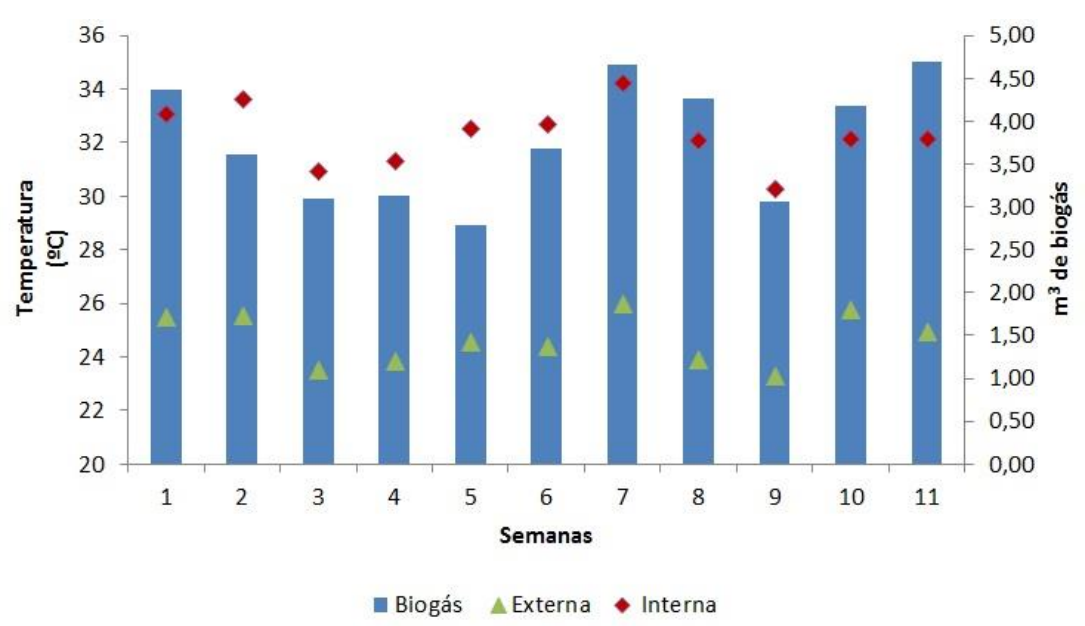

FIGURA 6: Média da produção de biogás acumulado na semana relacionada a média de temperatura interna e externa do biodigestor.

Observou-se na Figura 6, que a produção de biogás foi influenciada pela variabilidade das temperaturas interna e externa do biodigestor. Verifica-se que na $7^{\mathrm{a}}$ semana, a qual atingiu a maior média de temperatura interna $\left(34,20^{\circ} \mathrm{C}\right)$ e externa $\left(25,99^{\circ} \mathrm{C}\right)$, obteve-se também uma alta produção de biogás. Embora a média da temperatura interna do biodigestor tenha permanecido dentro da faixa ideal, a temperatura externa se manteve cerca de $7{ }^{\circ} \mathrm{C}$ abaixo da temperatura interna e, portanto, pode ter influenciado na menor produção de biogás em alguns períodos, como na $5^{\mathrm{a}}$ semana. Estes dados são confirmados pelo teste Tukey (5\%), conforme a Tabela 2, que mostra diferença significativa para a produção de biogás entre os tratamentos (semanas), tendo como melhores médias as semanas $11^{\mathrm{a}}$ e $7^{\mathrm{a}}$, resultados similares às semanas $10^{\mathrm{a}}, 1^{\mathrm{a}}, 8^{\mathrm{a}}$ e $6^{\mathrm{a}}$, que diferem estatisticamente apenas da $5^{\mathrm{a}}$ semana. A menor média foi para a $5^{\mathrm{a}}$ semana, não distinta às $6^{\mathrm{a}}, 2^{\mathrm{a}}, 3^{\mathrm{a}}, 9^{\mathrm{a}}$ e $4^{\mathrm{a}}$ semanas. 
TABELA 2: Teste de Tukey (comparação de médias).

\begin{tabular}{ccc}
\hline GRUPOS & TRATAMENTOS & MÉDIAS \\
\hline $\mathrm{a}$ & 11 & 4.808333 \\
$\mathrm{a}$ & 7 & 4.66 \\
$\mathrm{ab}$ & 10 & 4.345714 \\
$\mathrm{abc}$ & 1 & 4.257143 \\
$\mathrm{abcd}$ & 8 & 4.065714 \\
$\mathrm{abcde}$ & 6 & 3.835714 \\
$\mathrm{bcde}$ & 2 & 3.434286 \\
$\mathrm{bcde}$ & 3 & 3.291429 \\
$\mathrm{cde}$ & 9 & 3.168571 \\
$\mathrm{de}$ & 4 & 2.932857 \\
$\mathrm{e}$ & 5 & 2.794286 \\
\hline
\end{tabular}

Observa-se na Tabela 3 que a variação diária de temperatura foi alta, variando de 10,7 ${ }^{\circ} \mathrm{C}$ até $14,2{ }^{\circ} \mathrm{C}$, indicando que durante o período de temperatura mínima, nas madrugadas, a produção de biogás pode ter sido reduzida. Porém isso não se refletiu na média da semana, pois a temperatura máxima foi significativa, elevando essa média.

TABELA 3: Temperatura externa mínima, máxima e variação diária de temperatura de cada dia da $5^{\mathrm{a}}$ semana.

\begin{tabular}{cccc}
\hline DIA & $\begin{array}{c}\text { TEMPERATURA } \\
\text { MÍNIMA }\left({ }^{\mathbf{0}} \mathbf{C}\right)\end{array}$ & $\begin{array}{c}\text { TEMPERATURA } \\
\text { MÁXIMA }\left({ }^{\circ} \mathbf{C}\right)\end{array}$ & VARIAÇÃO $\left({ }^{\mathbf{0}} \mathbf{C}\right)$ \\
\hline $13 / 01 / 2013$ & 16 & 30,2 & 14,2 \\
$14 / 01 / 2013$ & 19,9 & 30,6 & 10,7 \\
$15 / 01 / 2013$ & 19,7 & 30,6 & 10,9 \\
$16 / 01 / 2013$ & 18,3 & 31,1 & 12,8 \\
$17 / 01 / 2013$ & 18,8 & 32,1 & 13,3 \\
$18 / 01 / 2013$ & 19,8 & 31,9 & 12,1 \\
$19 / 01 / 2013$ & 19,8 & 31,9 & 12,1 \\
\hline
\end{tabular}


Conforme Sosa et al. (1999), as bactérias mesofílicas são extremamente sensíveis a mudanças no meio, assim, variações bruscas de temperatura afetam o seu desempenho, podendo até mesmo levá-las a morte, o que acarreta na redução considerável da produção de biogás.

\section{Conclusão}

A partir dos dados obtidos de temperatura média nas regiões superior, intermediária e inferior do biodigestor, foi possível constatar que mesmo estas não estando em todos os horários dentro da faixa ideal de temperatura para a produção de biogás, se mantiveram dentro da faixa mesofílica, entre 20 e $45^{\circ} \mathrm{C}$, na qual se tem a combinação das melhores condições para o bom desenvolvimento do processo.

As temperaturas médias das regiões intermediária e inferior, internas ao biodigestor, seguiram o comportamento da temperatura externa ao biodigestor e a temperatura média da região superior foi influenciada pelos fatores externos e pela troca de energia entre as massas.

Os resultados mostram que não houve discrepância entre os teores $\mathrm{CH}_{4} \mathrm{e} \mathrm{CO}_{2}$ entre uma semana e outra, acompanhando a produção média de biogás. Os teores dos respectivos gases se mantiveram de acordo com a literatura e o teor de outros gases permaneceu abaixo de $1 \%$.

A produção de biogás pode ter sido influenciada pela variabilidade da temperatura. Variações bruscas de temperatura podem ter afetado a atividade das bactérias mesofílicas, resultando na redução da produção de biogás. 


\section{Referências Bibliográficas}

AMARAL, C. M. C.; AMARAL, L. A.; LUCAS JÚNIOR, J.; NASCIMENTO, A. A.; FERREIRA, D. S.; MACHADO, M. R. F. Biodigestão anaeróbia de dejetos de bovinos leiteiros submetidos a diferentes tempos de retenção hidráulica. Revista Ciência Rural, v. 34, n. 6, p. 1897-1902. 2004.

AMORIN, A. C.; LUCAS JÚNIOR, J.; RESENDE, K. T. Biodigestão anaeróbia de dejetos de caprinos obtidos nas diferentes estações do ano. Revista Engenharia Agrícola, v. 24, n. 1, p. 16-24. 2004.

CASTRO, L. R.; CORTEZ, L. A. B. Influência da temperatura no desempenho de biodigestores com esterco bovino. Revista Brasileira de Engenharia Agrícola e Ambiental, v. 2, n. 1, p. 97-102. 1998.

FARIA, R. A. P. Avaliação do potencial de geração de biogás e de produção de energia a partir da remoção da carga orgânica de uma estação de tratamento de esgoto - estudo de caso. 2012. 63 f. Dissertação (Mestrado em Energia na Agricultura) - Universidade Estadual do Oeste do Paraná, Cascavel, 2012.

FERREIRA, E. B.; CAVAlCANTI, P. P.; NOGUEIRA, D. A. ExpDes.pt: Experimental Designs package (Portuguese). R package version 1.1.2. 2013.

FERREIRA, E. Projeto técnico do sistema de produção do biogás. Folha nº 03/07. 2010.

HENN, A.; PHILIPPI, L. S.; GOSMANN, H. A.; WALTER, L.; BELLI FILHO, P. Planejamento ambiental e adequação à legislação ambiental de uma pequena propriedade suinícola com relação à geração, tratamento e destino dos dejetos suínos em Braço do Norte/SC. In: XXIX Congreso Interamericano de Ingenieria Sanitaria y Ambiental, San Juan, 2004.

IBGE. Instituto Brasileiro de Geografia e Estatística. Banco de Dados. 2011. Disponível em: <http://www.sidra.ibge.gov.br/bda/pecua/default.asp?t=2\&z=t\&o\%20=24\&u1=1\& $\mathrm{u} 2=1 \& \mathrm{u} 3=1 \& \mathrm{u} 4=1 \& \mathrm{u} 5=1 \& u 6=1 \& u 7=1>$. Acesso em: 28 de outubro de 2012.

IFCN. International Farm Comparison Network. A summary of results from the IFCN Dairy Report 2012. 6 p. 2012.

MACHADO, C. R.; XAVIER, C. A. N.; SILVA, A. A.; COSTA, L. V.; LUCAS JUNIOR, J. Produção de biogás utilizando dejetos de bovinos leiteiros com diferentes tempos de armazenamento com exposição ao ar. In: I Simpósio Internacional sobre Gerenciamento de Resíduos de Animais, p. 229-234. 2009.

MAURER, M.; WINKLER, J. P. Biogas Theoretishe Grundlagen, Bau und Betrieb von Anlagen. Karlsruhe: Verlag C.F. Müller, 1980. 142 p.

MIRANDA, A. P.; AMARAL, L. A.; LUCAS JÚNIOR, J. Influência da temperatura na biodigestão anaeróbia de dejetos de bovinos e suínos. In: X Encontro Latino Americano de Iniciação Científica e VI Encontro Latino Americano de Pós-Graduação - Universidade do Vale do Paraíba, p. 2928-2931. 2006. 
MONTEIRO, R. B. N. C. Desenvolvimento de um modelo para estimativas da produção de gases de efeito estufa em diferentes sistemas de produção de bovinos de corte. $2009.75 \mathrm{f}$. Dissertação (Mestrado em Agronomia) - Universidade de São Paulo, Escola Superior de Agronomia "Luiz de Queiroz", Piracicaba, 2009.

MOURA, J. P. Estudo de casos das rotas tecnológicas para produção de biogás e da influência da composição química de dejetos de matrizes suínas na qualidade do biogás gerada por biodigestor. 2012. 122 f. Dissertação (Mestrado) - Universidade Federal de Pernambuco, Recife, 2012.

NOGUEIRA, L. A. H. Biodigestão: a alternativa energética. São Paulo: Nobel, 1986. 93 p.

PECORA, V.; FIGUEIREDO, N. J. V.; COELHO, S. T.; VELÁZQUEZ, S. M. S. G. Nota Técnica VIII - Biogás e o mercado de crédito de carbono. In: Rio Oil \& Gas Expo and Conference 2008, Rio de Janeiro. 2008.

R Core Team. R: A language and environment for statistical computing. R Foundation for Statistical Computing, Vienna, Austria. URL http://www.R-project.org/. 2013.

SALOMON, K. R. Avaliação técnico-econômica e ambiental da utilização do biogás proveniente da biodigestão da vinhaça em tecnologias para geração de eletricidade. 2007. 219 f. Tese (Doutorado em Engenharia Mecânica) - Universidade Federal de Itajubá, Instituto de Engenharia Mecânica, Itajubá, 2007.

SOSA, R.; CHAO, R.; RÍO, J. Aspectos bioquimicos y tecnológicos del tratamiento de residuales agrícolas con producción de biogás. Instituto de Investigaciones Porcinas. 25 p. 1999.

SOUZA, C. F.; CAMPOS, J. A. Avaliação do tempo de retenção hidráulica, agitação e temperatura em biodigestores operando com dejetos de suínos. Revista Brasileira de Agroecologia, v. 2, n. 1, p. 1742-1745. 2007.

TOFFOLI, L. Corrente de convecção. Termodinâmica. InfoEscola. 2008. 